\title{
Dynamic Properties of Watertowers Assembled from InterlockedPanels under Different Loading Conditions
}

\author{
F. Gurkalo and K. Poutos
}

\begin{abstract}
Earthquakes produce some of the most violent loading situations that a structure can be subjected to and if a structure fails under these loads then inevitably human life is put at risk. One of the most common methods by which a structure fails under seismic loading is at the connection of structural elements.

The research presented in this paper compares the performance of mathematical models of watertowers under seismic conditions. One type of model is assembled withconcrete panels that are connected by means of a novel interlocked mechanism. The performance of this modelwas tested against the performance of a conventional monolith watertower. Two variables were appliedsimultaneously when testing each model: earthquakes with different magnitudes and different mass of the elevated water tanks.

The results of this experimental study demonstrated that across all tested seismic conditions, increasing the mass of the water tanks resulted in greater deformation of the watertowers. This was most pronounced for the monolith watertower model. With increasing mass of the water tanks across all seismic conditions, those watertowers composted of interlocked panels withstood increasing loading stresses more effectively than the monolith watertower.
\end{abstract}

Index Terms - Watertower, earthquake, ANSYS, seismic, interlocked panels.

\section{INTRODUCTION}

Many countries around the world are struggling of seismic activities. Importance of watertowers are huge especially in flat areas, where the watertower can be just a source of water to control fire during and after earthquake as well as control amount of drinking water for all people in that area. Thus, the water towers should not exceed the serviceability limit state and remain functional during and after severe ground motions.

There are a number of researches has been carried out regarding fluid-structure interaction and improvement of performance of water tanks [1] - [4]. However, just a few researches were conducted on the investigation and improvement of the reinforced concrete shafts [5],[6]. During resent earthquakes a number of water towers were collapsed or become non-functional as a result of the damages to the shaft due to low redundancy and poor ductility in thin reinforced concrete shafts.

Manuscript received August 9, 2012; revised September 14, 2012.

The authors are with Department of the Built Environment, Anglia Ruskin University, Chelmsford, CM1 1SQ, UK (e-mail: filip.gurkalo@anglia.ac.uk; konstantinos.poutos@anglia.ac.uk).
This paper presents a new system of assembling shafts for elevated water tanks using panels with interlocking mechanics. This method is based on the use of panels which are quickly assembled on site readily transported as a flat pack or in pre-formed modules. The panels can be potentially replaced after been damaged during an earthquake or other catastrophes without rebuilding a whole structure [7]. Moreover, the panels provide better ductility and lateral stress capacity for the shafts.

\section{CASE OF STUDY}

In this study three watertowers with same geometric properties and water tanks but different shafts were modeled. Model 1 was modeled as a watertower with a monolith shaft (Fig. 2a). Model 2 and Model 3 were modeled as watertowers composed of interlocked panels (Fig. 2b and 2c respectively). The integrated interlocked mechanism allowed rotation of panels in all directions in Model 2 and restricted any movements and rotations in vertical direction in Model 3.

Material for panels was assumed as concrete (Density $2300 \mathrm{~kg} / \mathrm{m}^{3}$; Poison ratio - 0.18 and Young's Modulus $3 \mathrm{e} 10^{10} \mathrm{~Pa}$ ) with frictionless contact between panels. The interlocked mechanism was modelled as a steel bar with 50 mm diameter. Bonded contact between steel bars and the concrete panels was assumed. Finite Element software ANSYS 14 Workbench [8] was employed for modelling watertowers.

Table I Geometric properties of the analysed watertowers a complete dynamic analysis of a structure which contains liquid, such as water tank, requires the hydrodynamics effect to be considered during the analysis. The hydrodynamics effect can be modelled using different simplified analytical methods such as single lumped-mass model or single degree of freedom (SDOF), two or more masses model, fluidstructure system and finite element model (FEM). A comparison and evaluation of these methods are presented by Livaoglu and Dogangun [9]. In this study, Water was modelled using fluid-structure interaction system by twomass model proposed by Hoursner [10] and Eurocod-8 method by using two degree of freedom (2DOF) springsystem of fluid-structure interaction (FSI) was adopted [11].

The towers were analysed under three different load conditions, masses inside water tanks: a - 300 tones, $\mathrm{b}-900$ tones and $\mathrm{c}-1800$ (Fig. 2). 


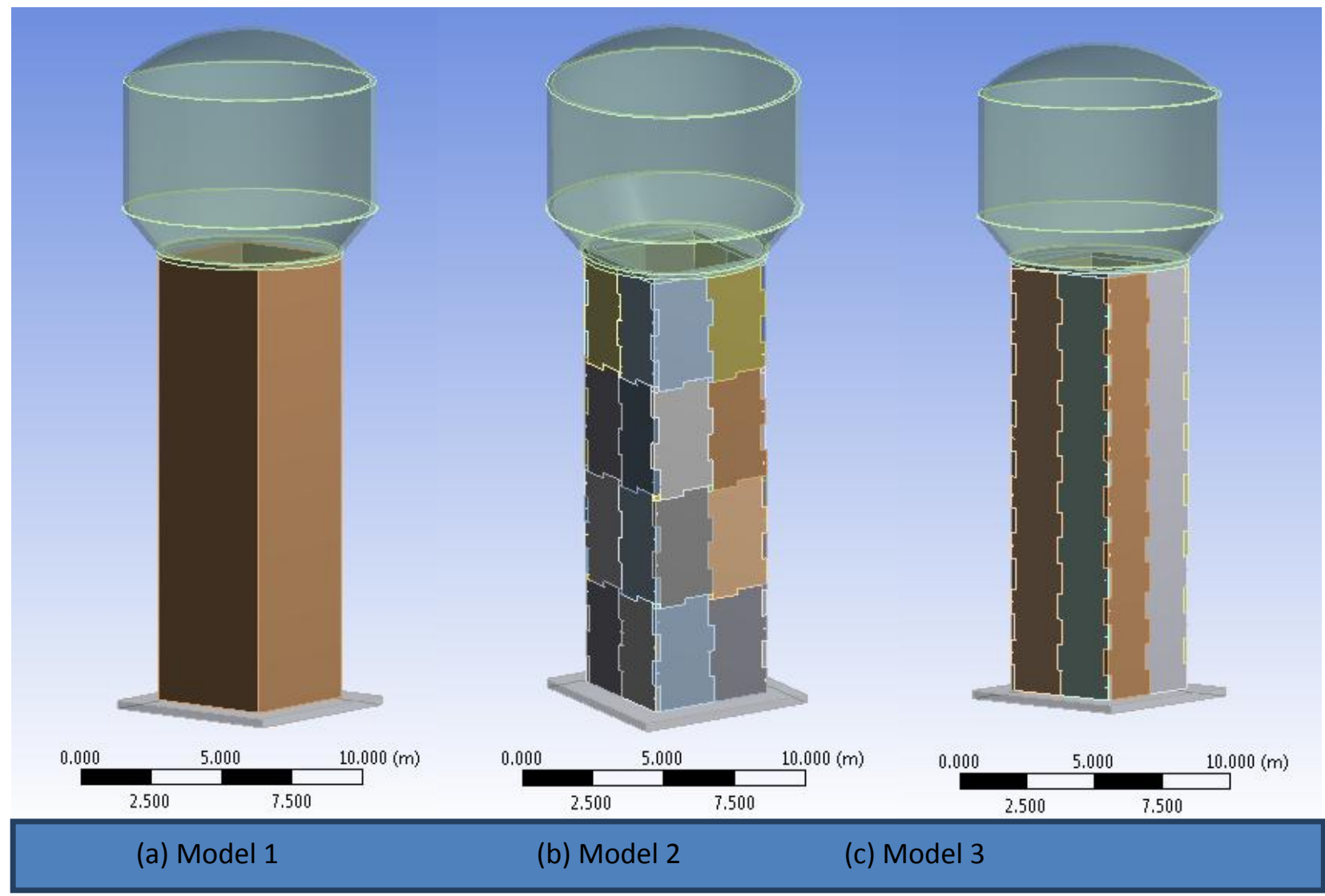

Fig. 1. Three models for analysis (a) Model 1 (b) Model 2 (c) Model 3

TABLE I: GEOMETRIC PROPERTIES OF THE ANALYSED WATER TANKS

\begin{tabular}{|l|l|l|l|}
\hline Vessel volume & $300 \mathrm{~m} 3$ & Bottom slab thickness & $0.3 \mathrm{~m}$ \\
\hline Height & $7.85 \mathrm{~m}$ & Mass of the empty vessel & $1,1526 \cdot 10^{5} \mathrm{~kg}$ \\
\hline Inner diameter & $8.6 \mathrm{~m}$ & Staging outer dimensions & $4.4 \times 4.4 \mathrm{~m}$ \\
\hline Vessel thickness & $0.2 \mathrm{~m}$ & Thickness of a staging & $0.2 \mathrm{~m}$ \\
\hline Roof thickness & $0.12 \mathrm{~m}$ & Foundation plate dimensions & $6.4 \times 6.4 \times 0.3 \mathrm{~m}$ \\
\hline Bottom slab diameter & $6.6 \mathrm{~m}$ & Length of a staging & $16 \mathrm{~m}$ \\
\hline
\end{tabular}

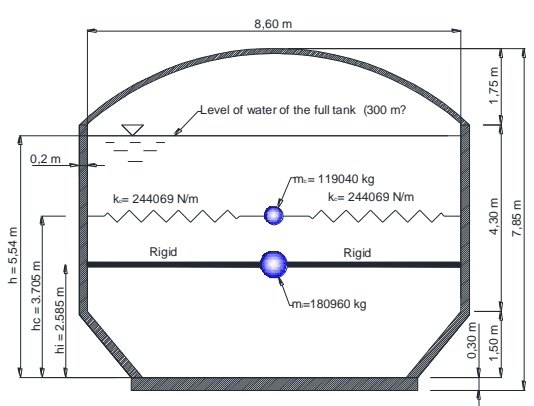

(a) Mass - $300 \mathrm{t}$

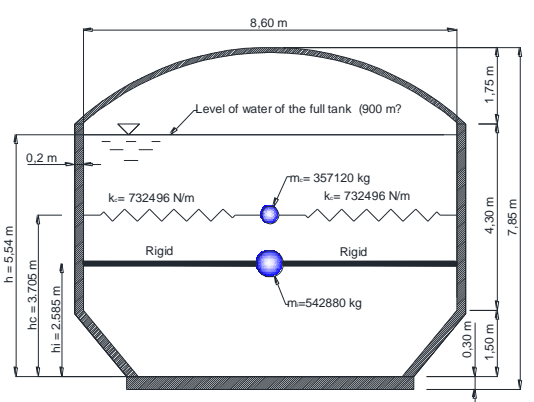

(b) Mass - $900 \mathrm{t}$

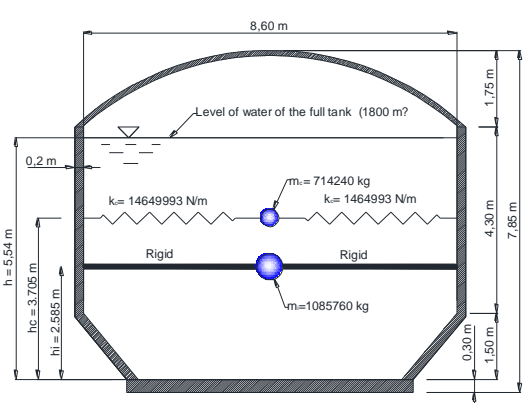

(c) Mass - $1800 \mathrm{t}$

Fig. 2. Modelled water tank with three different masses

Static, modal and response-spectrum analysis with Square Root of the Sum of the Squares (SRSS) method [12] were employed to determine seismic behavior of water towers. A response spectrum data of Yorba Linda, Norcia and Chi-Chi Taiwan earthquakes with magnitudes $4.26,5.9$ and 7.9 on the Richter scale were taken from The Pacific Earthquake Engineering Research Centre (PEER) ground motion database [13]. The modal and response-spectrum analysis were accomplished with respect to foundation plate been fixed to ground. 


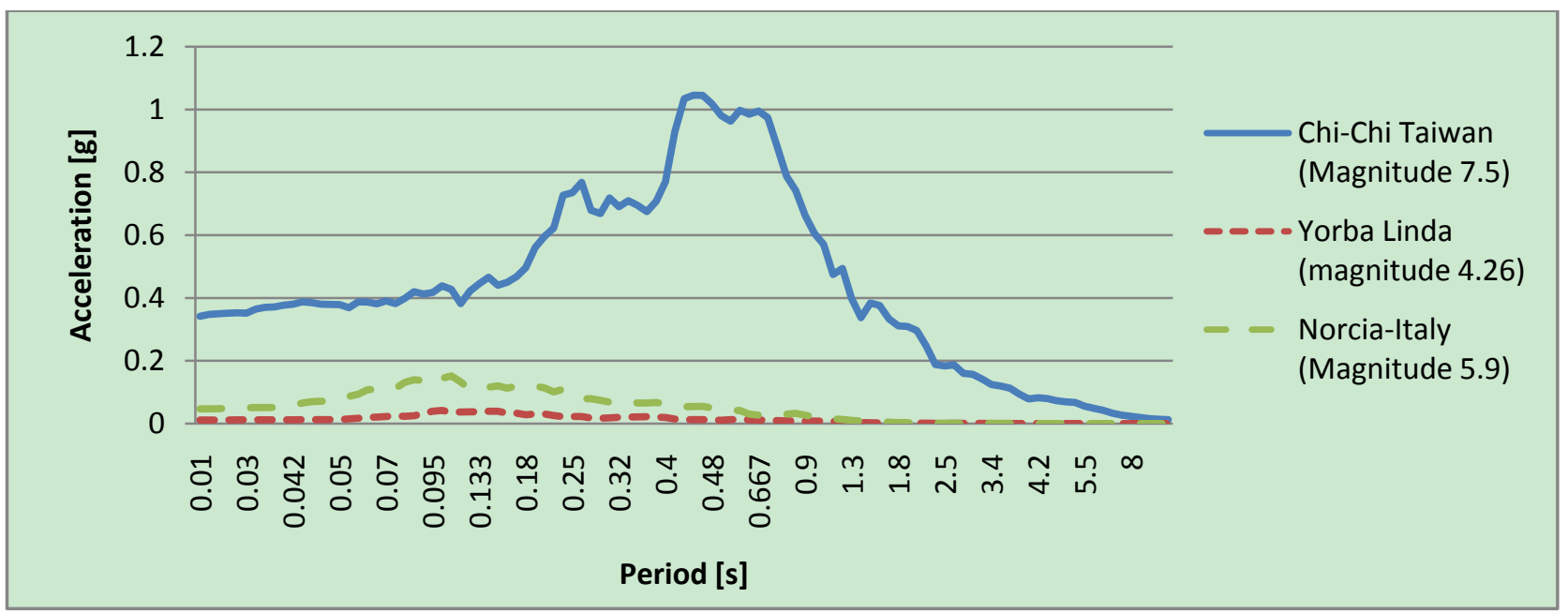

Fig. 3. Spectral acceleration of Yorba Linda, Norcia-Italy and Chi-Chi Taiwan horizontal records from PEER

\section{RESUlTS AND DISCUSSION}

The results of the maximum deformation are presented in Table II and Fig. 4.

TABLE II: MAXIMUM DEFORMATION OF THE MODELS UNDER EARTHQUAKE LOADS

\begin{tabular}{|c|c|c|c|c|c|c|c|c|c|}
\hline \multirow[t]{2}{*}{ Magnitude } & \multicolumn{9}{|c|}{ Models } \\
\hline & Model 1a & Model 2a & Model 3a & Model 1b & Model 2b & Model 3b & Model 1c & Model 2c & Model 3c \\
\hline 4.26 & 0.0010365 & 0.0008792 & 0.0007431 & 0.00154 & 0.0017367 & 0.0013913 & 0.0018908 & 0.0020525 & 0.0016164 \\
\hline 5.9 & 0.0033587 & 0.0034222 & 0.0027015 & 0.00491 & 0.0043353 & 0.0037072 & 0.0065606 & 0.0074999 & 0.0062553 \\
\hline 7.5 & 0.036604 & 0.057345 & 0.042151 & 0.11667 & 0.14185 & 0.11108 & 0.17176 & 0.1817 & 0.14748 \\
\hline
\end{tabular}

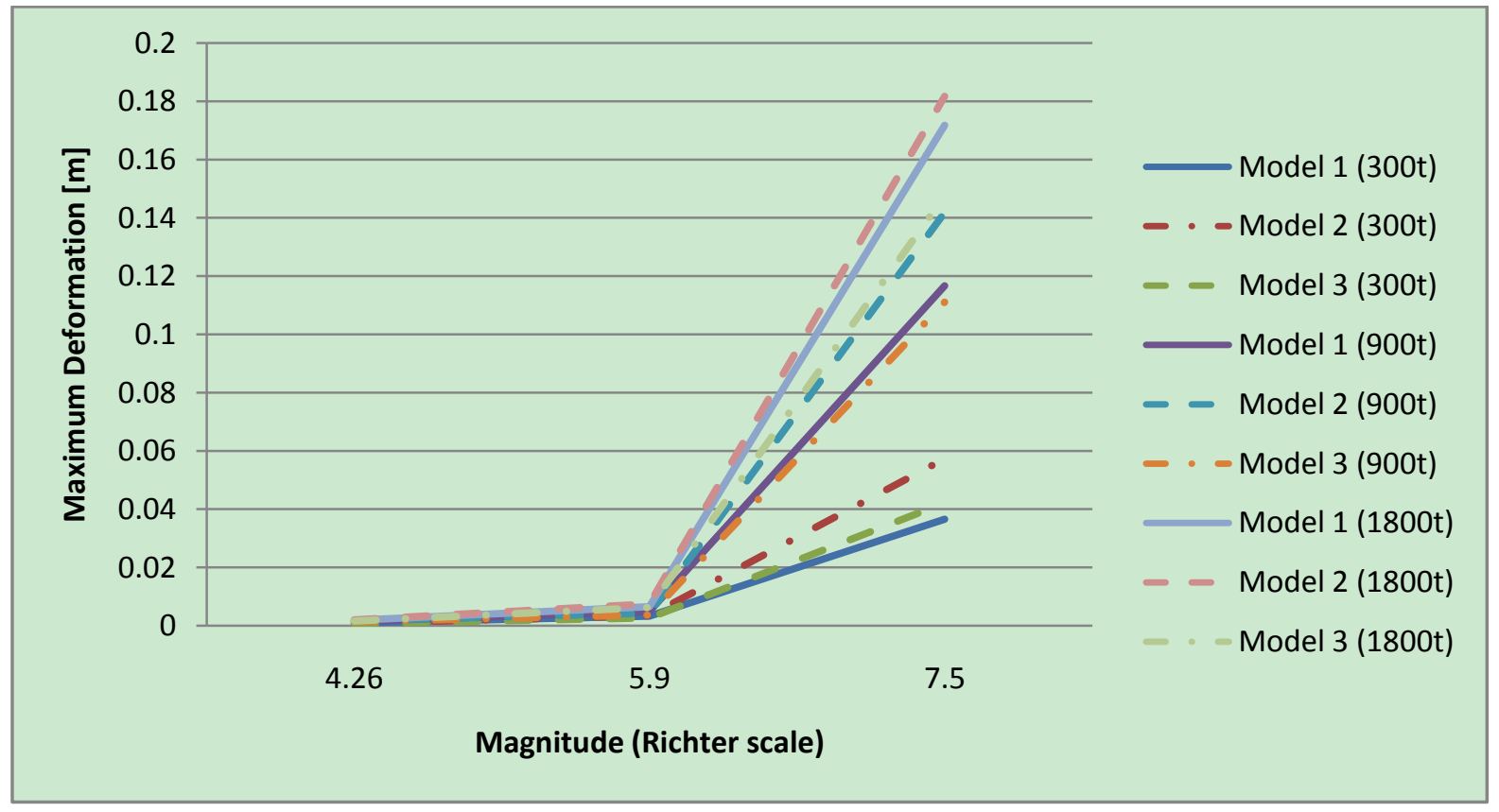

Fig. 4. Deformation of the models with different mass of water tank under earthquake loads

There was no significant difference in maximum deformation across the three models loaded with three experimental weights during Yorba Linda (magnitude 4.26) and Norcia-Italy (magnitude 5.9) earthquakes. The difference in deformation across the three models was most pronounced during Chi-Chi Taiwan (magnitude 7.5) earthquake.

Fig. 4 demonstrates that with increasing water tank mass under more severe earthquake conditions the deformation raises for all models, however the rate of deformation in 
model 1 is faster in comparison to model 2 and model 3. The deformation of the model 1aduring earthquake with magnitude 7.5 was $0.036604 \mathrm{~m}$ which is smaller than deformation of the model $2 \mathrm{a}$ and model $3 \mathrm{a}$ by $36 \%$ and $13 \%$ respectively. The deformation of model 1bduring earthquake with a magnitude 7.5 was $0.11667 \mathrm{~m}$ which is smaller than deformation of model $2 \mathrm{~b}$ by $18 \%$ but larger than deformation of model $3 \mathrm{~b}$ by $4 \%$. Finally, the deformation of model 1cduring earthquake with magnitude 7.5 was $0.17176 \mathrm{~m}$ which is smaller than deformation of model $2 \mathrm{c}$ by $5 \%$ but larger than deformation of model $3 \mathrm{c}$ by $14 \%$.

Fig. 5represents maximum deformation of all models under three conditions during Chi-Chi earthquake (magnitude 7.5). With increasing mass, the rate of maximal deformation was fastest in model 1 . The maximum deformation increased by $218 \%$ between model $1 \mathrm{a}$ and model $1 \mathrm{~b}$, and further increases by $47 \%$ between model $1 \mathrm{~b}$ and model 1c. Models $2 \mathrm{~b}$ and $3 \mathrm{~b}$ sustained 147\% and 164\% greater deformation compared to models $2 \mathrm{a}$ and $3 \mathrm{a}$ respectively, while models $2 \mathrm{c}$ and $3 \mathrm{c}$ sustained $28 \%$ and $33 \%$ greater deformation compared to models $2 \mathrm{~b}$ and $3 \mathrm{~b}$.

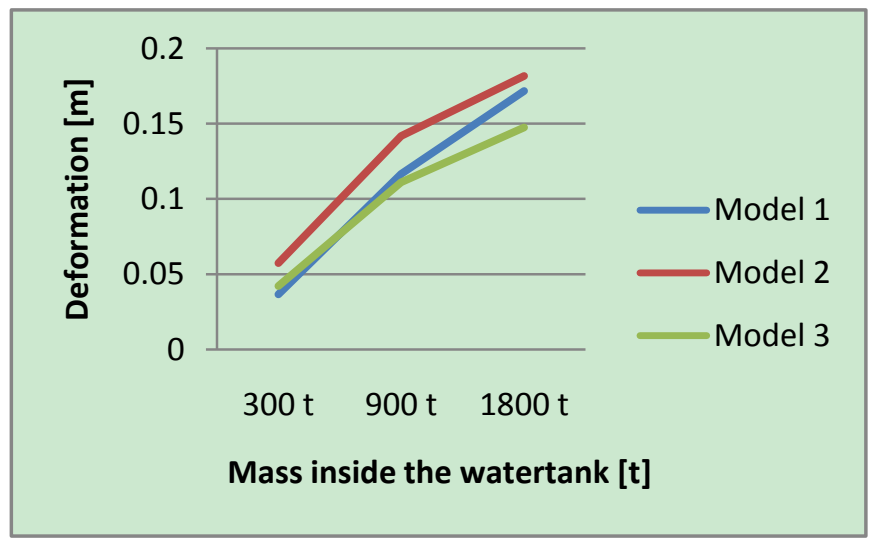

Fig. 5. Maximum deformation of the models with different mass of watertank under Chi-Chi earthquake

\section{CONCLUSIONS}

With increased magnitude of earthquakes, all models sustained increased deformation, and this occurred to the greatest extent for the models with the heaviest mass within the water tanks. Moreover, the most dramatic increase in deformation under these conditions was sustained by the monolith model.
With increasing mass within the water tanks, the dynamic properties of the water towers assembled from interlocked panels were improved to a greater degree compared to the monolith model.

Across all tested seismic conditions, increasing mass of the water tanks results in greater deformation of water towers. This is most pronounced for monolith water tower model.

With increasing mass of the water tanks across all earthquake conditions, the performance of water towers composted of interlocked panels was superior to that of the monolith water tower in withstanding seismic loads.

Further research is needed to investigate behaviour of water towers under other loading conditions, varying the height and geometric properties.

\section{REFERENCES}

[1] G. A. Algreane, S. A. Osman, O. Karim, and A. Kasa, "Behavior of Elevated Concrete Water Tank Subjected to Artificial Ground Motion," EJGE, vol. 16, pp. 387-406, 2011.

[2] P. K. Malhotra, T. Wenk, and M. Wieland, "Simple Procedure for Seismic Analysis of Liquid-Storage Tanks," Structural Engineering International, vol. 2, pp. 197-201, 2000.

[3] A. I. Gareane, G. A. Algreane, S. A. Osman, O. Karim, and A. Kasa, "Study the Fluid Interaction due to Dynamic Response of Elevated Concrete Water Tank," Australian Journal of Basic and Applied Science, vol. 5, no. 9, pp.1084-1087, 2011.

[4] M. M. Rakabawy, H. A. Arabaty, and M. G. Sherbiny, Response of Elevated Water Tanks to Seismic Loads. ICSGE, $11^{\text {th }}, 2005$.

[5] D. C. Rai, "Review of Code design Forces for Shaft Supports of Elevated Water tanks," $12^{\text {th }}$ Symposium on Earthquake Engineering, pp.1407-1418, 2002.

[6] F. Gurkalo and K. Poutos, "Dynamic Response of a Water Tower Composed of Interlocked Panels," World Academy of Science, Engineering and Technology, Issue 65, pp.444-450, 2012.

[7] AcerMetric@ $\odot 2010$ The AcerMetric $\odot$ System. [Online]. Available: http://www.acermetric.co.uk

[8] ANSYS, INC., 2009. Ansys Workbench user's guide.

[9] R. Livaoglu, and A. Dogangun, "Simplified seismic analysisprocedures for Elevated tanks considering fluid-structure interaction," Journal of Fluids and Structures, vol. 22, pp. 421-439, 2006.

[10] G. W. Housner, "The Dynamic Behaviour of Water Tanks," Bulletin of Seismological Society of America, vol. 53, no. 2, pp. 381-387, 1963.

[11] Design of structures for earthquake resistance - Part 4: Silos, tank and pipelines. European Committee for Stabilisation, Final PT Draft. Eurocode vol. 8, 2006.

[12] S. K. Jain and O. R. Jaiswal, "Modified proposed provisions for aseismic design of liquid storage tanks," Journal of Structural Engineering, vol. 32, no. 3-4, pp. 195-206, pp. 297-310, 2005.

[13] Pacific Earthquake Engineering Research Center, Users Manual for the PEER Ground Motion Database Web Application, 2011. 